\title{
El conocimiento del niño Haliti-Paresí acerca de hantavirus a través de expresiones artísticas
}

\author{
The Haliti-Paresí child's knowledge about hantavirus in artistic expressions \\ O conhecimento da criança Haliti-Paresí sobre a hantavirose através de \\ expressões artísticas
}

\section{Ana Cláudia Pereira Terças¹, Vagner Ferreira do Nascimento ${ }^{2}$, Thalise Yuri Hattori $^{3}$, Érica Baggio4, Marina Atanaka5 ${ }^{5}$ e Elba Regina Sampaio de Lemos ${ }^{6}$.}

\author{
${ }^{1}$ Enfermeira. Doutora em Medicina Tropical. Instituto Oswaldo Cruz, Fundação Oswaldo Cruz. e \\ Professora da Universidade do Estado de Mato Grosso (UNEMAT), campus de Tangará da Serra. Correo \\ electrónico: enfanacnp@gmail.com \\ ${ }^{2}$ Enfermeiro. Mestre em Terapia Intensiva. Professora Universidade do Estado do Mato Grosso, campus \\ Tangará da Serra. Correo electrónico: vagnerschon@hotmail.com \\ ${ }^{3}$ Enfermeira. Mestre em Ciências da Saúde. Professora Universidade do Estado do Mato Grosso, campus \\ Tangará da Serra. Correo electrónico: thalisehattori@gmail.com \\ ${ }^{4}$ Acadêmica de Enfermagem. Universidade do Estado do Mato Grosso, campus Tangará da Serra. Correo \\ electrónico: baggio.1994@hotmail.com \\ ${ }^{5}$ Enfermeira. Doutora em Saúde Coletiva Instituto de Saúde Coletiva, Universidade Federal de Mato \\ Grosso/UFMT. Correo electrónico: marina2.atanaka@gmail.com \\ ${ }^{6}$ Médica Infectologista. Doutora em Medicina Tropical. Pesquisadora Laboratório de Hantaviroses e \\ Rickettsioses, Instituto Oswaldo Cruz - FIOCRUZ. Correo electrónico: elba.lemos@ioc.fiocruz.br \\ Cómo citar este artículo en edición digital: Terças, A. C. P., Nascimento, V. F., Hattori, T. Y., Baggio, E., \\ Atanaka, M., \& Lemos, E. R. S. (2018). El conocimiento del niño Haliti-Paresí acerca de hantavirus a \\ través de expresiones artísticas. Cultura de los Cuidados (Edición digital), 22(51). Recuperado de \\ <http://dx.doi.org/10.14198/cuid.2018.51.11> \\ Correspondencia: Ana Cláudia Pereira Terças. Rua José Garcia Lacerda, 152N Centro. Tangará da Serra \\ - MT, Brasil. CEP: 78300-000. \\ Correo electrónico: ana.claudia@unemat.br \\ Recibido: 27/12/2017; Aceptado: 11/04/2018
}

\section{ABSTRACT}

Objective: To identify the knowledge of HalitiParesí children about hantaviruses through artistic expressions. Method: This is a descriptive-interpretative and qualitative study conducted with nine children of the HalitiParesí ethnicity through art therapy. The analysis of the design was performed using the single analysis recording technique. Results: We analyzed 14 graphic records of nine children in three categories: physical and social environment, knowledge about the transmission
\end{abstract}

of hantaviruses and knowledge about the disease/lethality. In the artistic expressions the presence of the reservoir of the disease was observed and the clinical severity with hospitalization images. Conclusion: The artistic productions of the children revealed the importance of educational and preventive measures that contribute to the improvement of the quality of life.

Keywords: Child rearing, design, hantavirus, health of indigenous peoples. 


\section{RESUMEN}

Objetivo: Se buscó identificar el conocimiento de los niños Haliti-Paresí sobre la hantavirose a través de las expresiones artísticas. Método: Se trata de un estudio del tipo descriptivointerpretativo y cualitativo conducido con nueve niños de la etnia Haliti-Paresí a través de la arteterapia, siendo el análisis de los diseños realizados utilizando la técnica de registro único de análisis. Resultados: Se analizaron 14 registros gráficos de nueve niños en tres categorías: ambiente físico y social; conocimiento sobre la transmisión de la hantavirose y el conocimiento sobre el agravio/letalidad. En las expresiones artísticas se observó la presencia del reservorio de la enfermedad y la gravedad clínica con imágenes de hospitalización. Conclusión: Las producciones artísticas de los niños desvelaron la importancia de medidas educativas y preventivas que contribuyan a la mejora de la calidad de vida.

Palabra-clave: Crianza del niño, diseño, hantavírus, salud de poblaciones indígenas.

\section{RESUMO}

Objetivo: Buscou-se identificar o conhecimento das crianças Haliti-Paresí sobre a hantavirose através de expressões artísticas. Método: Tratase de um estudo do tipo descritivo-interpretativo e qualitativo conduzido com nove crianças da etnia Haliti-Paresí através da arteterapia, sendo a análise dos desenhos realizada adotando-se a técnica de registro único de análise. Resultados: Foram analisados 14 registros gráficos de nove crianças em três categorias: ambiente físico e social; conhecimento sobre a transmissão da hantavirose e conhecimento sobre o agravo/letalidade. Nas expressões artísticas observou-se a presença do reservatório da doença e a gravidade clínica com imagens de hospitalização. Conclusão: As produções artísticas das crianças desvelaram a importância de medidas educativas e preventivas que contribuam para melhoria da qualidade de vida.

Palavra-chave: Educação infantil, desenho, hantavírus, saúde de populações indígenas.

\section{INTRODUÇÃO}

A população brasileira é composta por diversos povos sendo que os indígenas constituem 246 etnias, totalizando no Censo realizado em 2010 896.917 pessoas. Estão presentes nas várias regiões geográficas do país, com vulnerabilidades que relacionadas principalmente as perturbações ecológicas em massa ocorridas nos últimos anos (Santos \& Coimbra, 2013).

Esse cenário de modificação ambiental pode influenciar no processo saúde-doença desses povos, à medida que as diferentes pressões do eterno de suas terras podem desencadear 0 novas o surgimento de novas doenças, como a hantavirose, são potencializados, pela estreita relação entre o roedor reservatório e o homem, nesses ambientes antropizados (Terças, 2011).

A hantavirose pode se manifestar como uma doença viral aguda, febril e grave, transmitida pelo por roedores silvestres da família Cricetidae, que infectam os seres humanos na maioria dos casos por meio da inalação de vírus presente na urina, fezes ou saliva dos roedores infectados (Lemos \& Silva, 2015; Kruger, Figueiredo, Song, \& Klempa, 2015).

Essa doença apresenta um espectro clínico variável e mesmo com sugestão de unificação ainda é descrita sob duas síndromes clínicas sendo Síndrome Pulmonar por Hantavírus (SPH), específica das Américas (Lee, Lee, \& Johnson, 1978; Nichol et al., 1993; Vaheri et al., 2013).

No Brasil, está presente em 14 estados, sendo que Mato Grosso ocupa o primeiro lugar em casos de SPH com 310 registros até 2016, esses que se concentraram na região médio norte, região predominantemente agrícola e produtora de grãos, que sofreu impactos ambientais para dar espaço à monocultura (Salbé-Travassos da Rosa, 2008; Terças, 2011). Desde o registro dos primeiros em casos em Mato Grosso, a infecção atingia em sua maioria populações agrícolas, apesar de constatação sorológica em 2009 em aldeia do cerrado, apenas em 2010 esse cenário altera-se com o primeiro registro de casos humanos em indígenas Kayabi do parque indígena do Xingú (Oliveira et al., 2010; Terças et al., 2013), a partir de então, foram registrados casos anualmente em diferentes etnias matogrossenses.

$\mathrm{Na}$ região médio norte de Mato Grosso, responsável por $75 \%$ dos casos da doença no estado, está localizada a terra indígena Utiariti, onde residem os Haliti-Paresí, que até 2013 eram indenes para a SPH (Terças, 2011; Terças et al., 2016). Neste cenário, as crianças indígenas Haliti-Paresí constituem um grupo 
importante a ser investigado, pois além de residirem em área de intensa circulação de hantavírus, possuem maior contato com roedores silvestres em suas atividades diárias e brincadeiras, já que o brincar indígena está intrinsicamente ligado com a interação com fauna e flora. Assim o desvelar do conhecimento dessa população de estudo poderá auxiliar na compreensão dos processos de adoecimento, além de colaborar com aplicação de estratégias para intervenção desta grave doença (Zoia \& Peripolli, 2010).

Diante disso, o objetivo do estudo foi identificar o conhecimento das crianças Haliti-Paresí sobre a hantavirose através de expressões artísticas.

\section{METODOLOGIA}

Trata-se de um estudo do tipo descritivointerpretativo e qualitativo. A pesquisa descritivo-interpretativa se caracteriza por observar, analisar, correlacionar e descrever detalhadamente fatos e fenômenos, para posterior interpretação dos dados na tentativa de classificar e conceituar as informações (Cervo, Bervian, \& Silva, 2006).

O local de estudo é situado na aldeia localizada na terra indígena Utiariti, no chamado Chapadão Parecis na região médio norte do Estado de Mato Grosso. A aldeia possue 45 moradores e a escolha pelo público infantil se fundamenta na preocupação frente à vulnerabilidade biopsicossocial à qual as crianças se encontram expostas.

Incluíram-se nessa pesquisa nove crianças entre 2 a 12 anos, da etnia Haliti-Paresí, sendo excluídos aqueles menores de 2 anos, em decorrência dos traços produzidos não representarem um objeto claro, fato que dificultaria a interpretação (Rodrigues, 2010).

Para a coleta de dados, utilizou-se da técnica da arteterapia e como instrumento o desenho dirigido. A arteterapia utiliza como instrumento de diagnóstico e intervenção os recursos artísticos com a finalidade de conduzir o sujeito ao autoconhecimento, sua essência é a atividade artística e estética na comunicação em prol da saúde (Reis, 2014).

O período de coleta de dados ocorreu entre dezembro de 2014 e julho de 2015. A equipe de pesquisadores do estudo ficou imersa dentro da comunidade, doando-se ao registro sistemático em cadernos de campo e à experimentação de práticas tradicionais do viver desses povos. Para todas as crianças participantes do estudo foi disponibilizado 60 minutos, em local de livre escolha e uso de material gráfico (folhas sulfites A4, lápis grafite e de cor, giz de cera e borrachas), e a pintura dos desenhos foi de livre escolha, sem regras, ou limitações de cores e quantidade de desenhos. Apenas foi solicitado que realizassem a tarefa proposta "desenhar no papel o que sabe sobre hantavirose e colocar seu nome na folha para identificação”. Ao final foram recebidas 16 produções, destas, foram excluídas duas por não possuírem identificação, constituindo uma amostra final de 14 desenhos.

Para a análise dos desenhos, adotou-se a técnica de registro único de análise, sem recurso adicional de interpretação, categorizado por Silva (2010) como Unidade de Discurso. Para a análise das expressões artísticas recorreu às contribuições de três autores, Luquet (1969), Lowenfeld (1977) e Piaget (1975), que trazem várias características dos estágios de evolução do grafismo infantil.

Em um primeiro momento, foram relacionados todos os itens presentes no desenho, independente da existência de relação entre os mesmos ou lógica diante do contexto proposto. No segundo momento, compreendeu a relação existente entre os itens e o conhecimento da criança indígena sobre a doença hantavirose, com base nos referenciais utilizados.

A pesquisa foi conduzida de acordo com todos os padrões éticos, em observância a resolução 466/12, com aprovação da Comissão Nacional de Ética em Pesquisa sob $n^{\circ}$ 819.939/2014, CAAE: 04647412.0.1001.5541. Os responsáveis das crianças autorizaram que elas atuassem como participantes deste estudo e assinaram o Termo de Consentimento Livre e Esclarecido de Participação de Menor e o Termo de Assentimento.

\section{RESULTADOS E DISCUSSÃO}

Para a esse estudo, utilizou-se as produções científicas disponíveis sobre a temática, porém em virtude da ausência de estudos que analisassem esses fatores em crianças indígenas brasileiras, o caminho traçado pelos autores está pautado em estudos com crianças não indígenas do mesmo país por entender que em decorrência das adaptações culturais vividas ao longo dos anos pelos Haliti-Paresí, proximidade e inter- 
relação com os estilos de vida urbano, acesso facilitado aos meios de comunicação de massa e pela forte influência não indígena na formação educacional das crianças seja possível construir a análise.

Dessa forma, foram analisados 14 registros gráficos de nove crianças, sendo quatro do sexo feminino e cinco do sexo masculino. Os participantes tinham entre 3 e 11 anos, sendo uma criança de 3 anos, cinco crianças de 8 anos, uma criança de 9 anos e duas crianças de 11 anos. Portanto, a faixa etária predominante foi de 8 a 11 anos. Após o levantamento de todos os elementos contidos nos desenhos e préavaliação, emergiram-se três categorias (Quadro 1): Ambiente físico e social; Conhecimento sobre a transmissão da hantavirose e Conhecimento sobre o agravo/letalidade da doença.

$\mathrm{Na}$ primeira categoria, os elementos do ambiente físico e social que predominaram foram: árvore, sol, nuvem, a casa tradicional indígena e criança, com ilustrações presentes em sete desenhos. Dentre as expressões artísticas dos participantes de 8 a 11 anos, pelo menos um dos seus desenhos esses elementos se fez presente. Para Luquet (1969), a evolução do desenho se encontra associada ao desenvolvimento infantil, sendo distinguido por esse autor em quatro estágios: realismo fortuito, que se inicia por volta de 2 anos, realismo fracassado, que ocorre entre 3 a 4 anos, realismo intelectual, entre 4 a 10 ou 12 anos e realismo visual, geralmente por volta de 12 anos (Mèredieu, 2006).

No estágio do realismo intelectual, a criança tem a capacidade de expressar detalhes visíveis, invisíveis ou abstratos da ideia imaginária, buscando aproximá-lo o mais perto possível da realidade (Mèredieu, 2006). Tal característica pode ser constatada no primeiro desenho (expressão artística “a”) da Figura 1, onde os objetos ilustrados prevalentes revelam que o ambiente que transmite risco para o desenvolvimento da doença é a aldeia, ao desenharem elementos claros e comumente encontrados alí, mostrando conhecimento sobre a possibilidade de encontrarem roedores silvestres nesses locais, no período diurno. Ainda nessa fase, segundo Luquet (1969), “a criança desenha do objeto não aquilo que vê, mas aquilo que sabe”, ou seja, essas crianças provavelmente tiveram recordações de vivências ou de informações passadas em outros momentos que no local onde residem é vulnerável ao desenvolvimento da doença.

É importante ressaltar ainda que o desequilíbrio entre os fatores determinantes do processo saúde-doença são multicausais que podem estar relacionados a partir das representações socioculturais da doença em cada comunidade que se divide em três dimensões sendo ela a subjetiva (retrata quando ela se sente doente); biofísica (alterações orgânicas, perceptíveis); sociocultural (atribuída pelo grupo social) e quando vivenciados pela ótica infantil abrange novas dimensões (Roseiro \& Takayanagui, 2007).

O processo de adoecimento traz para o universo infantil vivências novas e ameaçadoras. $\mathrm{O}$ ato de adoecer carrega na maioria das vezes o peso da hospitalização, que impõe obstáculos para a rotina de vida, fato este presente na realidade de vida dessa etnia que busca nos serviços de saúde dos municípios circunvizinhos a assistência, quase sempre pautada na hospitalização e afastamento do cotidiano das aldeias. O processo de desenvolvimento global aliado à falta de recursos psíquicos para lidar com a realidade expõem a criança ao sofrimento tanto físico quanto psíquico, ou seja, traz consequências para o corpo e a mente infantil (Gonçalves et al., 2014).

Nesse sentido, os estudos psicanalíticos têm revelado que a criança constrói internamente o que está acontecendo no mundo externo e se utiliza da fantasia enquanto defesa. Sendo assim, cria-se o imaginário elas preferem recorrer à linguagem mímica ou não verbal para assim expressar fantasias dolorosas vivenciadas (Lepri, 2008).

O desenvolvimento intelectual e cognitivo da criança se encontra sustentado pelo contexto familiar. As oportunidades e estímulos que recebe desse meio é representando em seus desenhos e em suas brincadeiras. Alguns representam seus desenhos carregado nas cores, vivas e contrastantes; outros têm o traço mais leve, não carregam tanto na cor ou até utilizam tons claros. Alguns demonstram autonomia e determinação no momento da criação, decidem o que vão fazer e executam; outros são mais contidos até indecisos, mostrando em alguns momentos insegurança, apresenta necessidade de aprovação e muito incentivos (Souza, 2012). Segundo Lowenfeld (1977) "não existe duas 
crianças iguais e, de fato, cada criança difere do seu eu anterior à medida que constantemente cresce, compreende e interpreta o seu ambiente. A criança é um ser dinâmico; para ela a arte é uma comunicação do pensamento".

A ideia de pertencimento ao meio é indicada por crianças a partir de 7 anos por meio de um símbolo que utiliza no desenho chamado linha de base, onde os elementos ali representados denotam relação lógica entre si (Lowenfeld, 1977; Barbosa, 2013).

Na expressão artística “b” (Figura 1), utilizando as linhas de base ou dobragem, a criança expressa por meio da subjetividade, a dimensão do que quer representar, para dar a visão de perspectiva. A sequência de acontecimentos expressos em uma única imagem, juntamente com os elementos e suas relações, denotam evolução do processo de adoecimento, revelando desde a forma de contágio, a fatores prognósticos de insucesso. A criança tenta ainda retratar todo esse processo quando representa em seu cotidiano a presença do roedor silvestre em diferentes locais da aldeia.

A criança, desde pequena, é inserida em um ambiente estruturado de acordo com a realidade sociocultural. As interações que ela estabelece com os indivíduos e com o meio geram informações que são captadas e organizadas para posteriormente fundamentar a construção de suas representações sociais. Portanto, as representações aqui apreendidas são produções oriundas do seu processo de inserção social e cultural, ou seja, do conhecimento a priori deste ambiente que ela pertence, com reconstituições e modificações, combinações entre novos e antigos componentes (Ribeiro \& Pinto Junior, 2009; Gonçalves et al., 2014).

Algumas etnias possuem sua própria metodologia de aprendizado. Na representação Xikrin, por exemplo, esse momento de interação e aquisição de conhecimento ocorre durante a noite, quando as crianças escutam as histórias de seus avós, nas rápidas reuniões de família, além da grande contribuição da escola. Assim, observa-se que não há um momento e ocasião de aprendizado específico e único na cultura indígena, esse processo pode ocorrer a qualquer momento, com a pessoa que lhes parecer mais indicado, respeitando as regras de relações das diversas categorias de pessoas impostas pelo grupo (Cohn, 2000). As vivencias e processos de aprendizagem dos Haliti-Paresí corroboram com as descrições acima, pois as crianças são estão presentes em todas as relações da comunidade (Terças et al., 2016).

Uma das formas de promover saúde e prevenir doenças desse caráter é se utilizar do processo de educação em saúde, que por meio das ações educativas oportuniza o compartilhamento de saberes de acordo com suas necessidades, na busca de soluções das mais diversas problemáticas. Nesse sentido, é notório que as atividades de caráter preventivo são mais vantajosas que as de caráter curativista, tanto do ponto de vista econômico, quanto do ponto de vida assistencial. No cenário em questão, o papel da escola é fundamental, uma vez que constitui um dos alicerces da educação, da cidadania e da formação de uma nação (Costa, Figueredo, \& Ribeiro, 2013).

A escola é um espaço propício para educação em saúde, principalmente com o público infantil, que se inicia nesse momento sua educação, integração e inclusão social, que se estendem por toda a vida. A criança, inserida desde cedo nesse local, faz dele um ambiente propício para inúmeras descobertas, tornam-se multiplicadores de informações e adquirem a consciência do autocuidado. As crianças HalitiParesí, são incluídas no processo de ensino aprendizagem escolar precocemente, já que a escola na aldeia é frequentada por todas indiferente da idade, sendo o professor o ator responsável por incluí-las nas atividades diárias, estando ou não em idade escolar (Terças et al., 2016). Portanto, o enfermeiro pode se encontrar diante de uma oportunidade de identificar pessoas em vulnerabilidade em relação às questões ambientais e de saúde por meio das crianças.

O profissional da saúde, em especifico o enfermeiro enquanto “educador”, pode atuar junto aos professores, às famílias e aos alunos, na busca de promover educação em saúde no ambiente que o público infanto-juvenil se encontra, nesse caso, na aldeia, com a pactuação de parcerias que visem ações tanto do campo preventivo, quanto no de promoção da saúde, considerando os fatores de risco que assolam essa comunidade. É importante salientar que, para se ter um resultado satisfatório, é 
necessário considerar a relação professor/profissional de saúde, possibilitando a escuta de suas necessidades de todos os envolvidos, a fim de que todos participem do processo de mudança (Zoia \& Peripolli, 2010; Costa, Figueredo, \& Ribeiro, 2013).

A respeito da transmissão da hantavirose, as crianças demonstraram conhecimento direcionado ao reservatório da doença, ou seja, o roedor silvestre, ao representá-lo como principal vilão, podendo ser verificado sua presença em sete desenhos distintos. Além disso, as excretas (fezes) dos roedores foram lembradas em dois desenhos, demonstrando conhecimento que se associa com a transmissão da doença.

Segundo Lowenfeld (1977), existem três aspectos a serem considerados no desenho infantil: o exagero das unidades consideradas importantes, a negligência ou omissão de componentes menos importantes e a mudança de símbolos para partes significativas. Na Figura 1 (expressão artística “c”), a criança expressa a relevância do roedor silvestre nos aspectos relacionados a essa doença ao desenhálo ocupando uma plenitude significativa, ao centro da folha. Além disso, a ausência de outros elementos com a desconsideração da proporção do objeto caracteriza a afeição que lhe atribui (Mèredieu, 2006, Barbosa, 2013).

A transmissão do hantavírus para o homem ocorre principalmente pela inalação de partículas virais aerossolizadas, presentes nos excrementos e saliva dos roedores (Vaheri et al., 2013; Lemos \& Silva, 2015; Kruger, Figueiredo, Song, \& Klempa, 2015). Tal situação pode ser observada nas expressões artísticas das crianças e devem ser evitadas por meio de estratégias de prevenção para o controle dessa grave síndrome, uma vez que a rotina dessa população os expõe aos riscos de infecção, como as atividades de agricultura, coleta no cerrado em que acompanham seus pais, bem como as brincadeiras inseridas no ambiente silvestres, que realizam livremente (Terças et al., 2016).

A erradicação dos hospedeiros roedores não é factível, nem desejável, pela alteração importante que esta medida poderia induzir em seu ecossistema, entretanto uma maneira eficaz de diminuir o risco, consiste em limitar a exposição humana aos roedores infectados ou a locais fechados onde tenha infestação ativa por esses animais (Lemos \& Silva, 2015). Portanto, o ato de levar orientações específicas para a prevenção do contato com esses roedores constitui uma alternativa simples e eficaz, sendo de grande importância, principalmente com os públicos mais vulneráveis, como as crianças, que, além disso, constituem uma riquíssima fonte de disseminação de conhecimentos, uma vez que possuem uma maior facilidade de interagir com as pessoas a sua volta.

Já na expressão artística “d” (Figura 1), a imagem do roedor ganha uma concepção comum no ambiente retratado, ao ser representado por várias vezes consecutivas. A criança apresentou as excretas do roedor silvestre, indicando sua representatividade quer seja no imaginário artístico criativo, como na relação real do modo de infecção pela doença. Essa é uma característica particular da criança de desenhar os objetos, e essa expressão singular dá-se o nome de tipo. Pode-se observar um exemplo de tipo nesse desenho quando os vários roedores seguem as mesmas características e em basicamente todos eles a criança seguiu a mesma ordem de desenhar: cabeça, orelhas, tronco, pernas e rabo. Quando o tipo apresenta características como essa, de estabilidade, chama-se conservação do tipo, que se dá em grande parte pelo automatismo gráfico, quando se tem a repetição gráfica (Reis, 2014).

Nos estudos de Piaget (1975), o realismo visual é a fase que começa entre 8 e 9 anos, quando as relações na apresentação do espaço já estão constituídas. Nesse período, as crianças já se preocupam em respeitar as técnicas do desenho como distância, proporção e a perspectiva, que são apresentadas de forma integrada a essa representação gráfica. Existe uma relação entre os elementos que são apresentados por ligações entre linhas, curvas, ângulos ou distâncias (Mèredieu, 2006; Pereira, 2012). Nessa última categoria, que versa sobre o conhecimento sobre a gravidade/letalidade da hantavirose é possível identificar essas características. Os elementos retratados nos desenhos que fazem referência são: maca/cadeira de roda com pacientes presentes em cinco desenhos e hospital presente em dois desenhos.

Na expressão artística “e” (Figura 1), pode ser notada a relação entre os elementos (hospital, maca e paciente) com base nas linhas, ângulos e 
distâncias. Através dos objetos representados e da relação das partes é possível revelar o conhecimento da criança a respeito da gravidade da doença. Segundo Lowenfeld (1977), no período entre 9 a 12 anos, conhecido como Realismo, o desenvolvimento do senso crítico aflora permitindo um julgamento crítico pela produção (Barbosa, 2013).

Nesse mesmo desenho (expressão artística “e”), a criança expressa que na chegada e desenvolvimento da doença, a vida se tornar diferente e as atividades de rotina e aquelas que geram prazer são abandonadas, impondo-lhes limitações frente à doença, seja pelo distanciamento causado pela hospitalização, ao exigir a permanência em um ambiente não familiar, por vezes, frio e hostil como também pela repercussão de danos físicos, conforme ilustrado pela Figura 1 (expressão artística “f”) (Lepri, 2008; Gonçalves et al., 2014).

A expressão da hospitalização/hospital representa um local de privação, sofrimento, punição e castigo que remete a perspectiva do objeto como lócus da dor, doença e morte que ameaça o ser humano (Ribeiro \& Pinto Junior, 2009). Foucault (2001) ressalta ainda que a representação do hospital como um lugar da exclusão daquele que pode representar o mal só enfatiza a ideia de indissociabilidade entre o ser e a doença, sendo, portanto, o homem identificado por seu adoecimento, considerado como ruim logo retirado do convívio social e segregado a hospitalização, retratado pela expressão fácil característico de descontentamento.

Na expressão artística “e” (Figura 1) é possível identificar esse achado quando a criança desenha o hospital de uma maneira isolada e egocêntrica, associando a internação à gravidade do estado de saúde, logo, em uma forma mais extrema, um estado de solidão total, acompanhado pela ameaça de aniquilamento, desintegração e proximidade com a morte.

Ao desenhar, a criança deixa transparecer esses sentimentos, porém, apesar do desenho ser uma forma de representação espontânea, nem sempre serão desenvolvidos com a mesma facilidade e clareza. Nessas expressões artística, pode-se explorar as interpretações e conhecimentos relacionado à doença hantavirose de forma clara, objetiva e ordenhada. Essa facilidade pode estar relacionada com as fases de desenvolvimento relacionada à faixa etária determinante no estudo, devido aos estímulos que esses participantes recebem no seu meio familiar, que é fundamental na evolução do desenvolvimento infantil (Luquet, 1969; Piaget, 1975; Lowenfeld, 1977).

Segundo Tassinari (2007) as crianças indígenas têm liberdades de escolha que parecem impossíveis para nós, de cultura ocidental, já que quando as analisamos sempre olhamos pelo ponto de vista da tutela, as crianças indígenas no entanto são elementos-chave na socialização e na interação de grupos sociais e os adultos reconhecem nelas potencialidades que as permitem ocupar espaços de sujeitos plenos e produtores de sociabilidade.

Os indígenas adultos não manifestam tanta ansiedade de transmitir, seja o que for, às crianças, assim a onipresença das crianças nos diferentes espaços da aldeia, aponta a grande permissividade dos adultos aos seus comportamentos. O ativismo das crianças no processo de apropriação e produção da significação de cultura nativa por intermédio das interações nos grupos, com ou sem a presença de adultos, inseridos na construção sociocosmológica local da pessoa e do corpo, são bases fundamentais para o entendimento da formação, socialização e transição geracional do universo cultural “sobre a e da" infância (Domingues-Lopes, Oliveira, \& Beltrão, 2015). Tornando a aldeia e o território são espaços de sociabilidade e de educação, com os eventos sociopedagógicos acontecendo, por exemplo, a caminho do roçado, na mata, no rio; enquanto se praticam as atividades rotineiras (Cohn, 2000).

Assim, um ponto de partida importante para o estudo dessas populações seria a mudança do olhar de quem se volta para a criança, sem apenas a perspectiva do ensinar. Escutá-las mais, observá-las mais, entender como se dá o processo de socialização, sem a intenção de pedagogizar todos os seus movimentos, as suas brincadeiras, os momentos que fazem parte do diálogo que estabelecem com o mundo. É nesse movimento de dar voz a criança indígena por meio de suas expressões, que percebemos suas representatividades culturais que podem justificar seus comportamentos em relação ao processo saúde-doença da comunidade (Munarim, 2011).

Talvez, em razão disso, os desenhos analisados no estudo tenham retratado com tanta fidedignidade a transmissão e consequência da 
hantavirose, visto que nesta comunidade indígena houve um caso confirmado da doença em 2013, com agravamento e hospitalização em unidade de terapia intensiva.

A criança indígena e sua família têm necessidades de cuidados, seja para ajudar a resgatar as suas próprias tradições de cuidado ou, o cuidado preventivo e curativo, se preciso for, sem impor a eles uma nova cultura, um novo modo de ser. Temos que pensar no índio, sem atitudes paternalista, como um ser com necessidades de múltiplas assistências, essencialmente holística e humanizada. Assim, acreditamos que a Enfermagem possui todos esses recursos para efetivação das práticas do cuidar, por ser uma profissão, cujo enfoque é o cuidado ao ser humano, à família e à comunidade em suas dimensões transculturais e transpessoais (Zoia \& Peripolli, 2010; Costa, Figueredo, \& Ribeiro, 2013).

Mas, esse cuidado só ocorrerá em sua totalidade quando os profissionais repensarem suas práticas de se despirem do etnocentrismo em seu cotidiano, já que a criança indígena e seu grupo familiar necessitam diuturnamente de ações que reduzam as iniquidades a que estão expostas.

\section{CONCLUSÃO}

Observou-se que o desenho é um instrumento de grande valia para desvendar o imaginário infantil, no qual a criança consegue expressar os elementos que constitui seu pensamento, possibilitando identificar o que permeia seu contexto de vida. Além de apresentar suas percepções que definem o seu comportamento.

As crianças investigadas consideraram o ambiente onde vivem de risco ao contato e/ou desenvolvimento da hantavirose. E, ao representarem em mais da metade dos desenhos o roedor silvestre, demonstram conhecer aspectos importantes da doença. Alguns desenhos exibiram ainda a presença dos roedores fora da mata, o que levanta possibilidade de contato próximo e convivência com esses animais no espaço domiciliar. Com relação à gravidade da doença, algumas crianças demonstraram conhecimento, relacionado à hospitalização e ao prognóstico, porém em um quantitativo reduzido de expressões.

A convivência com esses roedores, às vezes harmoniosas e afetivamente sendo chamados de "ratinhos" pode ter impedido o reconhecimento de informações referente à prevenção da doença. Além disso, o conhecimento dos adultos e as relações destes com a natureza pode ter refletido nas percepções das crianças que partilham desse mesmo contexto no seu desenvolvimento.

Frente a esse cenário, o trabalho dos enfermeiros em atividades de educação em saúde, como fonte de promoção da saúde e prevenção de doenças tendem a ser uma estratégia enriquecedora da prática em saúde, por possuir potencialidades que podem percorrer vários espaços nas relações sociais dos indígenas, fortalecendo práticas culturais de proteção e contribuindo para elevação do nível de vida.

\section{REFERÊNCIAS}

Barbosa, M. N. S. (2013). Criação, imaginação $e$ expressão da criança: caminhos $e$ possibilidades do desenho infantil (Tesis de maestría). São João Del-Rei: Universidade Federal de São João Del-Rei.

Cervo, A. L., Bervian, P. A., \& Silva, R. (2006). Metodologia Científica. São Paulo: Pearson Prentice Hall.

Cohn, C. (2000). Crescendo como um Xikrin: uma análise da infância e do desenvolvimento infantil entre os Kayapó-Xikrin do Bacajaú. Revista de Antropologia. 43(2), 195-222.

Costa, G.M., Figueredo, R.C., \& Ribeiro, M.S. (2013). A importância do enfermeiro junto ao pse nas ações de educação em saúde em uma escola municipal de Gurupi - TO. Revista Científica do ITPAC. 6(2): 1-12. Recuperada de http://www.itpac.br/arquivos/Revista/62/6.pdf Domingues-Lopes, R.C., Oliveira, A.C., \& Beltrão, J. F. (2015). O lúdico em questão: brinquedos e brincadeiras indígenas. Desidades.6, 25-39. Recuperada de http://pepsic.bvsalud.org/scielo.php?script=sci arttext\&pid=S2318-92822015000100003.

Foucault, M. (2001). Microfísica do poder. Rio de Janeiro: Edições Graal.

Gonçalves, A. N., Bortolotti, F. S, Menezes, M., Broering C.V., \& Crepaldi M.A. (2014). Memórias sobre cirurgias eletivas: o que expressam as crianças. Revista da SBPH. 17(1), 05-25. Recuperada de http://pepsic.bvsalud.org/scielo.php?script=sci $\underline{\text { arttext\&pid=S1516-08582014000100002 }}$ 
Kruger, D. H., Figueiredo, L. T. M., Song, J. W., \& Klempa B. (2015). HantavirusesGlobally emerging pathogens. Journal of Clinical Virology 64,128-136. Recuperada de http://koreauniv.pure.elsevier.com/en/publicatio ns/hantavirusesglobally-emerging-

pathogens(a5ef314f-d120-4454-9a4e-

8d0e73b02609).html

Lee H. W., Lee P. W., \& Johnson K. M. (1978). Isolation of the etiologic agent of Korean hemorrhagic fever. J Infect Dis.137:298-308.

Lemos, E. R. S., \& Silva, M. V. (2015). Hantavírus. Rio de Janeiro: Guanabara Koogan.

Lepri, P. M. F. (2008). A criança e a doença: da fantasia à realidade. Rev Sociedade Brasileira de Psicologia Hospitalar. 11: 15-26. Recuperada de http://pepsic.bvsalud.org/scielo.php?script=sci arttext\&pid=S1516-08582008000200003

Luquet, G. H. (1969). O desenho infantil. Porto: Ed. Minho.

Lowenfeld, V. (1977). A criança e sua arte. São Paulo: Mestre Jou.

Mèredieu, F. (2006). O desenho infantil. São Paulo: Editora Cultrix.

Munarim, I. (2011). O que podemos aprender com as crianças indígenas? Aproximações da antropologia da criança às noções da infância, cultura e movimento na educação física. Rev Bras Ciênc Esporte. 33(2), 375-90. Recuperada de

http://revista.cbce.org.br/index.php/RBCE/articl e/view/614.

-Nichol, S. T., Spiropoulou C. F., Morzunow S., \& et al. (1993). Genetic Identification of a hantavírus associated with an outbreak of acute respiratory illness. Science. 262:914-917. Recuperada de http://www.ncbi.nlm.nih.gov/pubmed/8235615 Oliveira, R. C., Gomes, R., Carvalho, V. H. G., Figueiredo, J. F., Anschau, I., Jesus, S., \& et al. (2010). Hantavirus seroprevalence in Brazilian Indian Community. In: Abstract Book VIII International Conference on HFRS, HPS and Hantaviruses. Athenas: Internacional society for hantaviruses and hantaviral diseases.

Pereira, C.L. (2012). Piaget, Vygotsky e Wallon: contribuições para os estudos da linguagem. Psicologia em Estudo. 17(2), 277286.

Piaget, J. (1975). A formação do símbolo na criança: imitação, jogo, sonho e representação. Rio de Janeiro: Zahar.
Reis, A. C. (2014). Arteterapia: a Arte como Instrumento no Trabalho do Psicólogo. Psicologia: Ciência e Profissão. 34(1):142-157. Recuperada de http://www.scielo.br/scielo.php?pid=S14149893 2014000100011\&script $=$ sci abstract\&tlng $=\mathrm{t}$

Ribeiro, C. R., \& Pinto Junior, A. A. (2009). A representação social da criança hospitalizada: um estudo por meio do procedimento de desenho-estória com tema. Revista da SBPH. 12(1), 31-56. Recuperada de http://pepsic.bvsalud.org/scielo.php?script=sci_ arttext\&pid=S1516-08582009000100004

Rodrigues, M.H. (2010). Análise do Desenho Infantil segundo as Ideias de Luquet. Revista da Unifebe - Online. 2(8),12-29. Recuperada de https://www.unifebe.edu.br/revistadaunifebe/20 10/artigo012.pdf

Roseiro, M. N. V., \& Takayanagui, A. M. M. (2007). Novos indicadores no processo saúdedoença. Saude. 33(1), 37-42. Recuperada de http://periodicos.ufsm.br/revistasaude/article/vie w/6462

Salbé-Travassos da Rosa, E. Associação vírushospedeiro e epidemiologia molecular de hantavírus em distintos ecossistemas amazônicos: Maranhão e Pará - Mato Grosso (Tesis de doctorado). Rio de Janeiro: Instituto Oswaldo Cruz.

Santos, R. V., \& Coimbra, Jr. C. E. A. (2013). Cenários e tendências da saúde e da epidemiologia dos povos indígenas no Brasil. Rio de Janeiro: Editora Fiocruz.

Silva, A. A. F. (2010) Utilização do desenho como instrumento para análise da percepção de risco e medo no trânsito (Tesis de maestría) Rio de Janeiro: Universidade Federal do Rio de Janeiro.

Souza, S. H. V. (2012). A criança e a expressão do pensamento através do grafismo. Rev Thema. 9(2), 1-23. Recuperada de http://revistathema.ifsul.edu.br/index.php/thema /article/view/135

Tassinari, A. (2007). Concepções Indígenas de Infância no Brasil. Revista Tellus. 7(13), 11-25. Recuperada de http://www.gpec.ucdb.br/projetos/tellus/index.p hp/tellus/article/view/138

Terças, A. C. P. (2011). Emergência da síndrome cardiopulmonar por hantavírus em Mato Grosso: aspectos epidemiológicos e clínicos durante o período de 1999-2010. (Tesis 
de maestría). Mato Grosso: Universidade Federal de Mato Grosso.

Terças, A. C. P., Nascimento, V.F. Hattori, T.Y. Zenazokenae, L.E., Atanaka, M., \& Lemos, E. R. S. (2016). Os Haliti-Paresí: uma reflexão sobre saúde e demografia da população residente nas terras indígenas Paresí. Revista Espaço Ameríndio. 10(01),226-253. Recuperada de

http://seer.ufrgs.br/index.php/EspacoAmerindio/ article/view/60301

Terças, A. C. P., Santos M. A., Pignatti M., Espinosa M. M., Via A. V. G. M., \& Menegatti J. A. (2013). Hantavirus Pulmonary Syndrome Outbreak, Brazil, December 2009-January 2010. Emerging Infectious Diseases. 19:11. Recuperada https://wwwnc.cdc.gov/eid/article/19/11/120463_article

Vaheri, A., Strandin, T., Hepojoki, J., Sironen, T., Henttonen, H., Mäkelä, S., \& Mustonen, J. (2013). Uncovering the mysteries of hantavirus infections. Nature Reviews Microbiology. 11, 539-550. Recuperada de http://www.nature.com/nrmicro/journal/v11/ n8/abs/nrmicro3066.html

- Zoia, A., \& Peripolli, O. J. (2010). Infância indígena e outras infâncias. Espaço Ameríndio. 4(2): 9-24. Recuperada de http://seer.ufrgs.br/EspacoAmerindio/article/vie $\mathrm{w} / 12647$.

Quadro I - Categorização dos elementos visualizados nas expressões artísticas de indígenas HalitiParesí, julho de 2015. Tangará da Serra - MT, Brasil.

\begin{tabular}{|c|c|c|}
\hline CATEGORIA & Elementos & $\begin{array}{r}\text { Total de } \\
\text { desenhos }\end{array}$ \\
\hline \multirow{8}{*}{ Ambiente físico e social } & Árvore & 7 \\
\hline & Sol & 7 \\
\hline & Nuvem & 7 \\
\hline & Rio & 2 \\
\hline & Casa tradicional indígena & 7 \\
\hline & Escola & 2 \\
\hline & Criança & 7 \\
\hline & Adulto & 4 \\
\hline \multirow{2}{*}{$\begin{array}{l}\text { Conhecimento sobre a } \\
\text { transmissão da Hantavirose }\end{array}$} & Roedor & 7 \\
\hline & Excretas (fezes do rato) & 2 \\
\hline \multirow{3}{*}{$\begin{array}{l}\text { Conhecimento sobre o } \\
\text { agravo/letalidade da doença }\end{array}$} & Hospital & 2 \\
\hline & Maca/cadeira de roda & 5 \\
\hline & Paciente & 5 \\
\hline
\end{tabular}


Figura 1 - Expressão artística livre de criança indígena Haliti-Paresi de 11 anos, em resposta ao questionamento: O que você sabe sobre Hantavirose? Julho de 2015 Tangará da Serra - MT, Brasil.

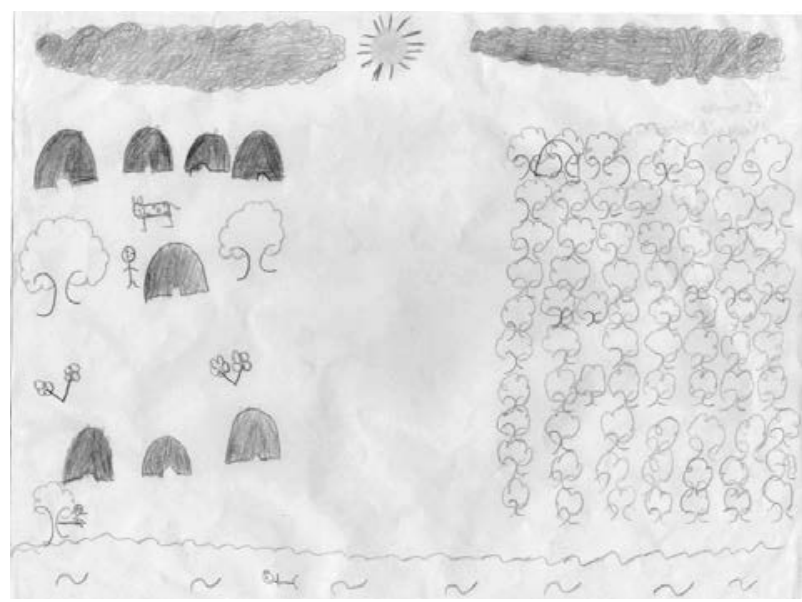

Figura 2 - Expressão artística livre de criança indígena HalitiParesi de 9 anos, em resposta ao questionamento: O que você

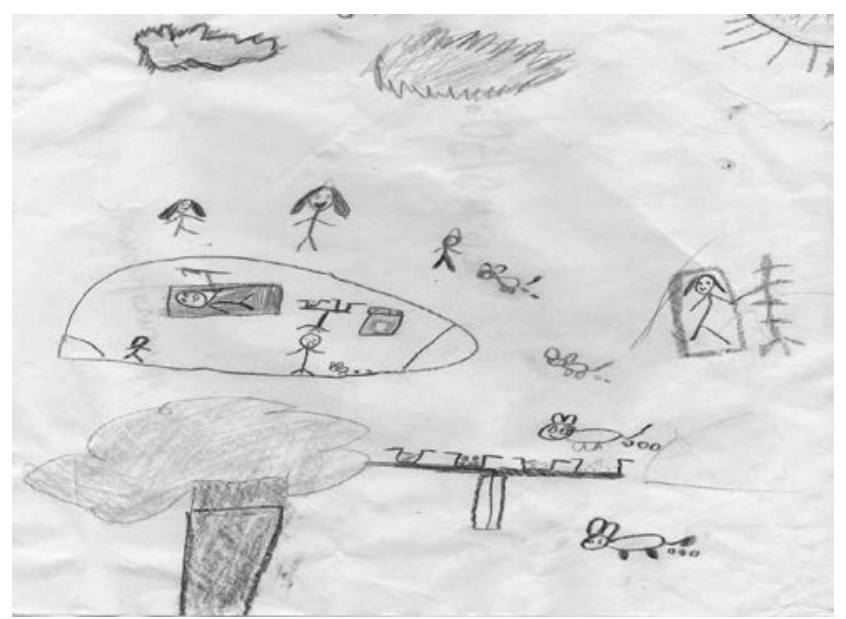

Figura 3 - Expressão artística livre de criança indígena HalitiParesi com 11 anos, em resposta ao questionamento: O que você sabe sobre Hantavirose? Julho de 2015 Tangará da Serra - MT, Dn: 1
Figura 4 - Expressão artística livre de criança indígena Haliti-Paresi de 8 anos, em resposta ao questionamento: O que você sabe sobre Hantavirose? Julho de 2015 Tangará da Serra - MT, Brasil.

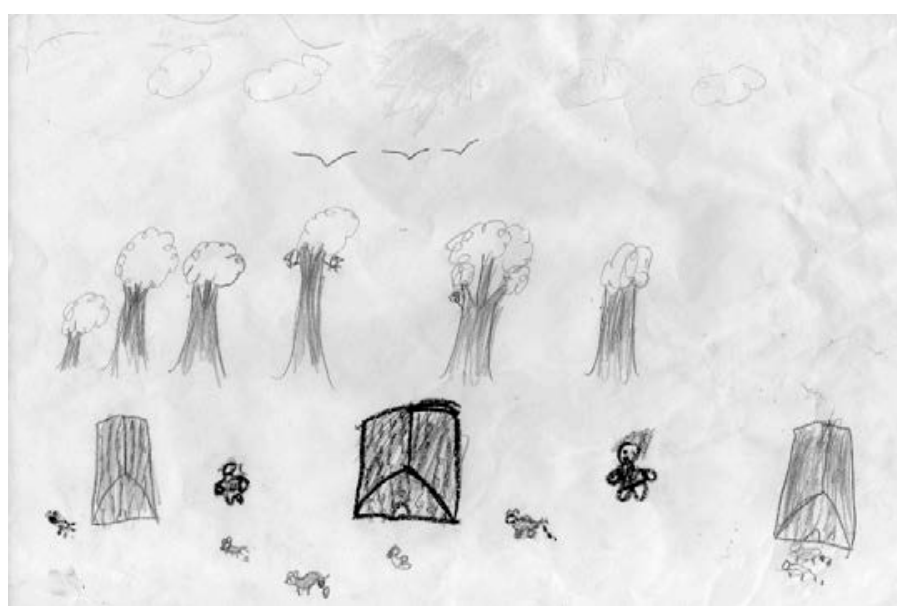

Figura 5 - Expressão artística livre de criança indígena Haliti-Paresi de 9 anos, em resposta ao questionamento: O que você sabe sobre Hantavirose? Julho de 2015 Tangará da Serra - MT, Brasil.

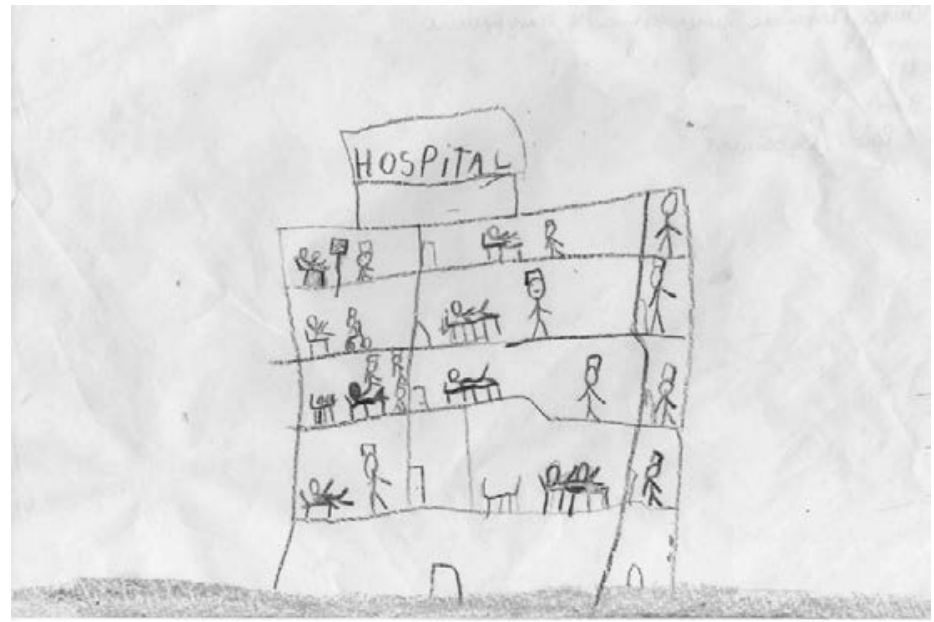

Figura 6 - Expressão artística livre de criança indígena Haliti-Paresi de 8 anos, em resposta ao questionamento: O que você sabe sobre Hantavirose? Julho de 2015 Tangará da Serra - MT, Brasil.

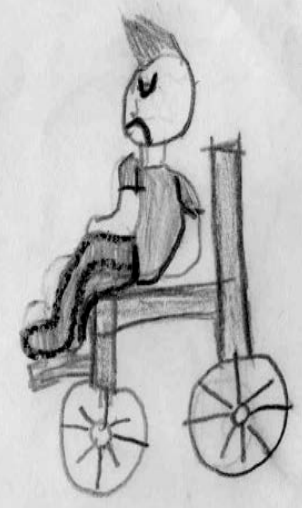

